\title{
Impact of climate change on water availability in the Oueme catchment at the outlet of the Save's bridge (Benin, West Africa)
}

\author{
Amedée Chabi $^{1,2}$, Esdras Babadjidé Josué Zandagba ${ }^{1,2}$, Ezekiel Obada $^{1,2}$, Eliezer Iboukoun Biao $^{1,2}$, \\ Eric Adéchina Alamou ${ }^{1,2}$, and Abel Afouda ${ }^{1}$ \\ ${ }^{1}$ Laboratory of Applied Hydrology, National Water Institut, Abomey-Calavi, Benin \\ ${ }^{2}$ Laboratoire de Géosciences de l'Environnement et Applications/Université Nationale des Sciences, \\ Technologies, Ingénierie et Mathématiques (UNSTIM), Abomey, Benin
}

Correspondence: Amedée Chabi (amedeechabi1@gmail.com)

Published: 16 November 2021

\begin{abstract}
One of the major threats to water resources today remains climate change. The objective of this study is to assess the impact of climate change on water availability in Oueme catchment at Savè. Precipitation provided by three regional climate models (RCMs) was analyzed. Bias in these data was first corrected using the Empirical Quantile Mapping (EQM) method be for etheir use as input to hydrological models. To achieve the objective, six hydrological models were used (AWBM, ModHyPMA, HBV, GR4J, SimHyd and Hymod). In projection, the results showed that the AWBM model appears to be the best. The multi-model approach further improves model performance, with the best obtained with combinations of the models AWBM-ModHyPMA-HBV. The AWBM model showed a fairly good capability for simulating flows in the basin with only HIRHAM5 climate model data as input. Therefore, the simulation with the HIRHAM5 data as inputs to the five (05) hydrological models, showed flows that vary at the horizons (2025, 2055 and 2085) under the scenarios (RCP4.5 and RCP8.5). Indeed, this variation is largely due to anthropogenic greenhouse gas (GHG) emissions.
\end{abstract}

\section{Introduction}

The successive reports of the Intergovernmental Panel on Climate Change (IPCC) have confirmed that major climate changes are under way and their effects are now proven. The first volume of the fifth report, published in 2013, reveals that, projections for 2100 depend on human activities and model uncertainties (Quae, 2013). Indeed, the planet is warming up because of man-made greenhouse gas emissions (IPCC, 2014). Due to its geographical location, West Africa will suffer more from the consequences of climate change. Indeed, it is marked by the repeated drought which has worsened since the 1970s and 1980s. This vulnerability to climate disturbances is due to the diversity of impacts, multiple stresses, greater magnitude and low adaptive capacity (Obada, 2017). A decrease in average annual rainfall of $20 \%$ to $40 \%$ was also observed between 1931-1960 and 19681990 (IPCC, 2007), which led to a greater drop in the flow of rivers from $40 \%$ to $60 \%$, and was followed by increased vulnerability to natural disasters (Afouda et al 2007). The Oueme catchment at Savè is not spared from these climatic variations. There is a considerable decrease in the amount of water available, and this decrease is aggravated with the current context of climate change. It is therefore necessary to understand the relationships between hydrological functions and all interactions with climate. Thus, the study of the impacts of climate change on river flows in the Oueme catchment at Savè is of paramount importance in order to better develop adaptation policies. This study aims to assess the impacts of climate change on water availability in the Oueme catchment at Save. 


\section{Study area and methodology}

\subsection{Study area and data}

The Oueme catchment at Savè covers an area of approximately $23600 \mathrm{~km}^{2}$. it is located between $8^{\circ} 00^{\prime} 40^{\prime \prime}$ and $10^{\circ} 03^{\prime} 20$ Lat. North, $1^{\circ} 30^{\prime} 20^{\prime \prime}$ and $2^{\circ} 32^{\prime} 25^{\prime \prime}$ Long. East (Le Barbé and Borel, 1987). The climate in this basin is tropical, but with a strong tendency towards the Sudanese type. It is characterized by two main seasons: a dry season (November to March) and a rainy season (April to October) (Akognongbe, 2007; Zandagba, 2012) (Fig. 1). The data used in this study are of two types: The observed daily hydro climatic data (precipitation, potential evapotranspiration (PET) and flow rates). They have been extracted from the database of Meteo-Benin and General Direction of Water of Benin, and covering the period of 1960 to 2014. Simulated data from regional climate models (RCM) (precipitation and PET). The period 1970 to 2005 has been chosen as reference period and 2006 to 2100 was chosen for future projection. All these data come from the CORDEX AFRICA https://cordex. org/data-access/regional-climate-change.simulation (last access: 18 June 2020) project database and have a spatial resolution of $0.5^{\circ} \times 0.5^{\circ}$.

\subsection{Methods}

\subsubsection{Bias correction}

To extract data from a grid of $0.5 \times 0.5^{\circ}$ spatial resolution, the EQM method has been used. This downscaling method preserves the long-term absolute (relative) trend of the simulated temperature or precipitation data and modify the daily variability of the simulated data about their monthly means to match the observed daily variability.This method uses empirical distribution functions (Sennikovs and Bethers, 2009) and is constructed by calculating empirical Probability Distribution Functions (PDF) and then using Cumulative Distribution Functions (CDF) for correction (Eq. 1):

$Y=F_{\text {obs }}^{-1}\left(F_{\mathrm{MCR}}(x)\right)$

where $Y$ is the bias corrected value of the meteorological parameter and $x$ its value simulated by the model; $F_{\mathrm{MCR}}$ is the CDF (Cumulative Distribution Function) of the data simulated by the MCRs and $F_{\text {obs }}^{-1}$ is the inverse of the CDF of the observed data

\subsubsection{Hydrological modeling}

In order to characterize the impacts of climate change on the availability of water resources in the Oueme catchment at Savè, the rainfall and PET resulting from the correction of the biases of the 03 investigated RCMs are used as input data to 06 hydrological models (Table 1).

The selected hydrological models have been calibrated from1974 to 1978 and validated from 2003 to 2007. Indeed, these periods has been chosen because of the availability of continuous data and necessity to considered different type of period (wet and dry period) which must be distinct from each other, in order to appreciate the robustness of the used model.

\subsubsection{Performance criteria}

The performance of both bias correction methods and models is evaluated using the Nash-Sutcliffe Efficiency Coefficient (NSE) (Nashand Sutcliffe, 1970), percent bias (PBIAS) (Guptaetal., 1999), root mean square deviation or square base error (RMSE), which in corporate both the variance of the estimate and its bias (Lehmannand Casella, 1998) and the error (RSR).

\subsubsection{Analysis of the rate of variation of river discharge}

Future changes relative to the reference period (1970-2005) are evaluated from Eq. (2). For this purpose, we have chosen to study the impacts of climate change over three (03) projection sub-periods: 2014-2040 (horizon, 2025), 2041-2070 (horizon, 2055) and 2071-2100 (horizon, 2085) to assess the changes in the investigated hydroclimatic series according to the RCP4.5 and RCP8.5 scenarios.

change rate $=\frac{\bar{X}_{\mathrm{P}}-\bar{X}_{\mathrm{r}}}{\bar{X}_{\mathrm{r}}} \times 100$,

Where $\bar{X}_{\mathrm{P}}$ the average of the hydro climatic parameter is over the projection period considered and $\bar{X}_{\mathrm{r}}$ is the average of the series over the reference period.

\section{Results and discussions}

\subsection{Rainfall bias correction performance}

Figure 2 shows an example of performance of the EQM method in the correction of the biases of precipitations simulated by the models HIRHAM5, REMO, RCA4 and their ensemble. From the analysis of this figure, it can be seen that the corrected monthly precipitation data are close to those of the observations.

\subsection{Performance of hydrological models and multi-models}

Table 2 and Fig. 3 show the performance of models and multi-models in calibration and validation. From the analysis of Fig. 3, it was found that AWBM, ModHyPMA, HBV, GR4J models give good performance in calibration and validation with Nash performance criteria of over $60 \%$. In view of the results obtained and the number of parameters which characterize each of these hydrological models considered in this study, AWBM model appears superior to the others in terms of performance. From the analysis of Fig. 3, it also emerges that the multi-models AWBM-ModHyPMA-HBV 


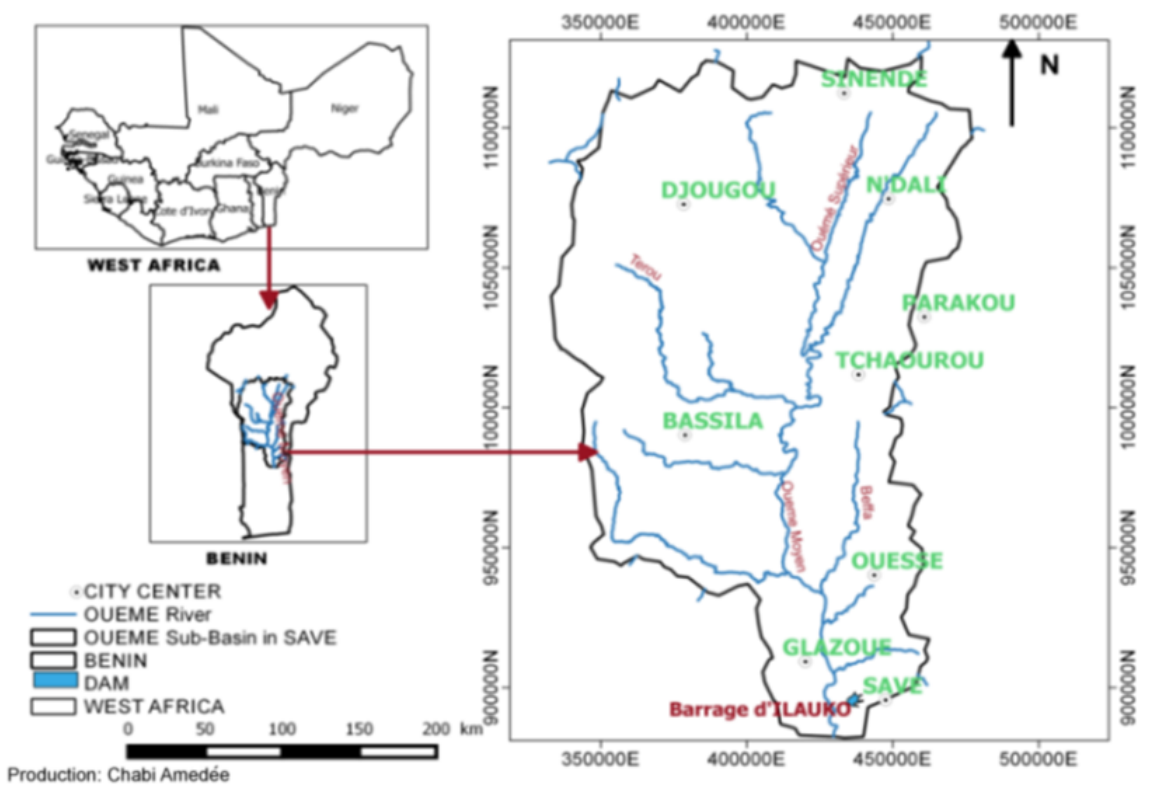

Figure 1. Geographic location in the Oueme at Save catchment.

Table 1. Description of selected models.

\begin{tabular}{llrrll}
\hline Modèle & Formal & Par & Res & Forcage & References \\
\hline ModPMA & Phys & 2 & - & $P, \mathrm{ETP}+Q$ & Afouda et al. (2010) \\
GR4J & Conp & 4 & 3 & $P, \mathrm{ETP}+Q$ & Perrin (2000) \\
HBV & Conp & 9 & 3 & $P, \mathrm{ETP}+Q$ & Bergström and Forsman (1973) \\
SimHyd & Conp & 7 & 2 & $P, \mathrm{ETP}+Q$ & Chiew and Siriwardena (2005) \\
AWBM & Conp & 7 & 3 & $P, \mathrm{ETP}+Q$ & Boughton (1993) \\
Hymod & Conp & 5 & 4 & $P, \mathrm{ETP}+Q$ & Boyle (2001) \\
\hline
\end{tabular}

Formal $=$ Formalisme, Par $=$ Parameters, Res $=$ Number of returns Comp $=$ Conceptuel, ETP $+Q($ calage $)$.

Table 2. Performance of hydrological models in calibration and validation.

\begin{tabular}{lcccccc}
\hline Modèles & ModHyPMA & GR4J & HBV & SimHyd & AWBM & Hymod \\
\hline \multicolumn{7}{c}{ Calage (01-01-1974 au 31-12-1978) } \\
\hline NSE & 0.82 & 0.83 & 0.85 & 0.86 & 0.89 & 0.56 \\
$R^{2}$ & 0.85 & 0.86 & 0.86 & 0.86 & 0.88 & 0.65 \\
RMSE & 0.25 & 0.30 & 0.23 & 0.23 & 0.19 & 0.38 \\
MAE & 0.05 & 0.13 & 0.02 & 0.04 & 0.01 & 0.12 \\
\hline \multicolumn{7}{c}{ Validation $(01-01-2003$ au 31-01-2007) } \\
\hline NSE & 0.70 & 0.75 & 0.81 & 0.65 & 0.82 & 0.54 \\
$R^{2}$ & 0.73 & 0.79 & 0.81 & 0.83 & 0.85 & 0.74 \\
RMSE & 0.5 & 0.42 & 0.37 & 0.51 & 0.36 & 0.57 \\
MAE & 0.00 & 0.14 & 0.03 & 0.11 & 0.01 & 0.15 \\
\hline
\end{tabular}

and the ensemble of the five models show good performance with the Nash value of 0.90 in calibration and 0.81 in validation.
Table 3. Comparison of RCMs data as in put to reproduce observed flow.

\begin{tabular}{lcrrr|rrrr}
\hline & \multicolumn{4}{c|}{ Calibration } & \multicolumn{4}{c}{ Validation } \\
\cline { 2 - 9 } Mod data & NSE & $R^{2}$ & RMSE & MAE & NSE & $R^{2}$ & RMSE & MAE \\
\hline HIRH5 & 0.51 & 0.51 & 0.42 & 0.01 & 0.50 & 0.50 & 0.4 & 0.10 \\
REMO & 0.31 & 0.30 & 0.48 & 0.00 & 0.30 & 0.4 & 0.69 & 0.18 \\
RCA4 & 0.25 & 0.25 & 0.51 & 0.01 & 0.22 & 0.35 & 0.74 & 0.15 \\
Ensemble & 0.34 & 0.34 & 0.47 & 0.00 & 0.40 & 0.50 & 0.65 & 0.13 \\
\hline
\end{tabular}

\subsection{Comparison of performance of AWBM models for different input data of RCMs}

Figure 4, shows the performance of the AWBM model in calibration and validation with different climatic model data. The Analysis of this figure shows that HIRHAM5 models data using allow to get the best flow estimation on the basin has showed by NSE and $R^{2}$ value of 0.51 in calibration against 0.50 in validation (Table 3 ). The values of RMSE and MAE obtained are relatively low for each data item of the RCM models considered. In view of all the above, it emerges 

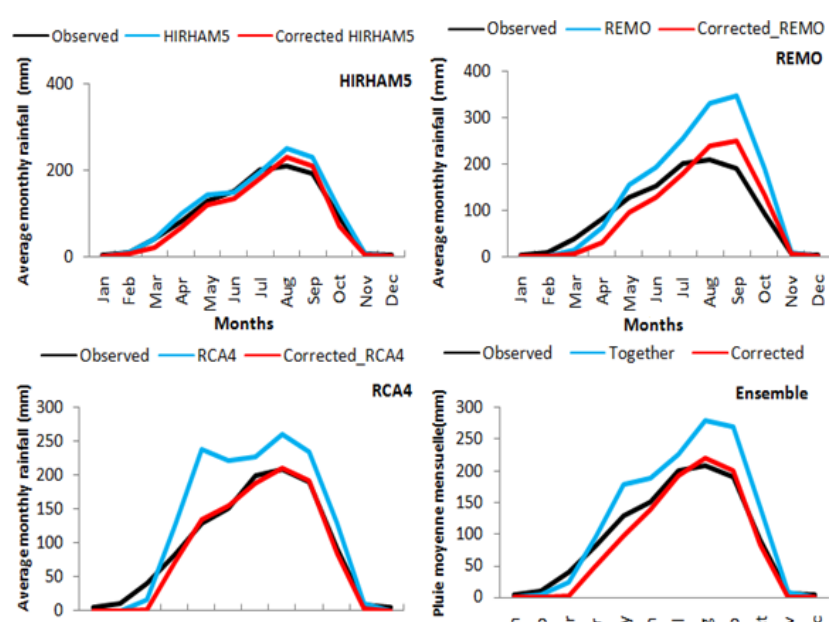

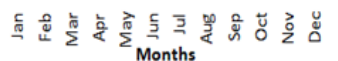

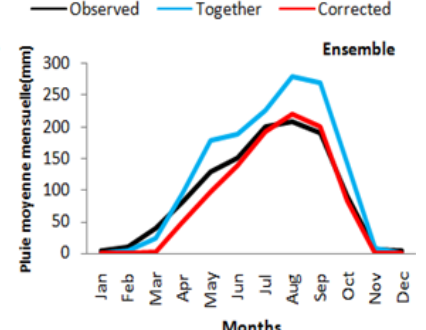

Figure 2. Performance of the EQM method in correcting biases in simulated precipitation by (HIRHAM5, REMO, and RCA4) and the ensemble of RCMs over the period 1970-2005.

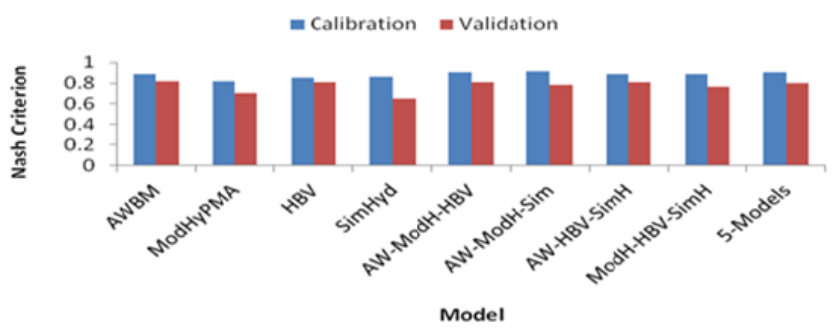

Figure 3. Performance of M-M to 3 and the ensemble of 05 models.

from this analysis that, AWBM model, showed a fairly good capacity for the simulation of the flows in the basin with only the data of HIRHAM5 as inputs.

\subsection{Evolution of annual average flows}

Figure 5 shows the evolution of the mean annual flows in the basin from the HIRHAM5 data as inputs to the 05hydrological models considered together. Under the RCP4.5 scenario, the simulation with the five (05) models predicts by 2025 an increase of the flows, with an average value of $0.37 \mathrm{~mm} /$ day compare to observations period. By 2055, a slight decrease in flows compared to observations with an average of $0.35 \mathrm{~mm} /$ day, lower than observations mean can be observed. By 2085, we will observe a strong increase of the flows with an average of $0.45 \mathrm{~mm} /$ day, which is significantly higher compare to observations period with an equivalent change rate of $19.07 \%$. Under the RCP8.5 scenario, the simulation with the 05 -models predicts a strong increase in the flows at the horizons 2055 and 2085 respectively with the mean of 0.4 and $0.51 \mathrm{~mm} /$ day, and is higher than those of the observation period. During this horizon, we note a rate of change of $19.56 \%$ by 2085 . By 2025 the models predict a
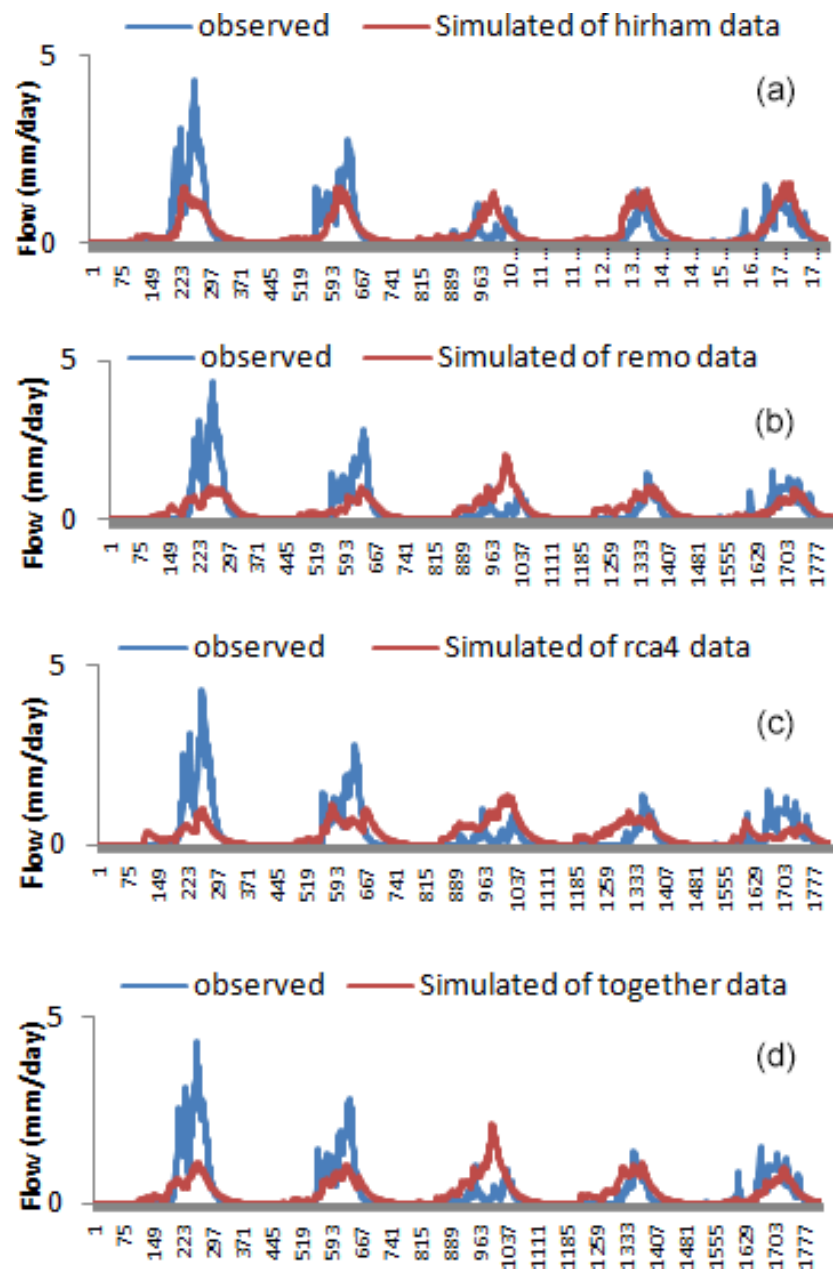

Figure 4. Comparison of observed and A flows for different input data.

slight decrease of the flows with an average of $0.30 \mathrm{~mm} /$ day. Overall, the horizons 2055 and 2085 will be more affected by a strong increase in flows under the RCP8.5 scenario than under the RCP4.5 scenario.

\subsection{Discussion}

The applications of the models (AWBM, ModHyPMA, HBV, GR4J and SimHyd) give convincing results in terms of performance with quality criteria of more than $60 \%$ from Nash. These results are consistent with those of (Paturel et al., 2009). In fact, these authors have shown that a performance criterion greater than $60 \%$ indicates a satisfactory performance of the hydrological model in the reproduction of the basin flows. It can also be noticed that the combination in the case of a multi-model can gradually improve the performance of the models in calibration by an average of $1 \%$ and $2 \%$ in validation. Consequently, it would be appropriate to use a combination of hydrological models for the prediction of flows in the Ouémé to Savè basin instead of a single 

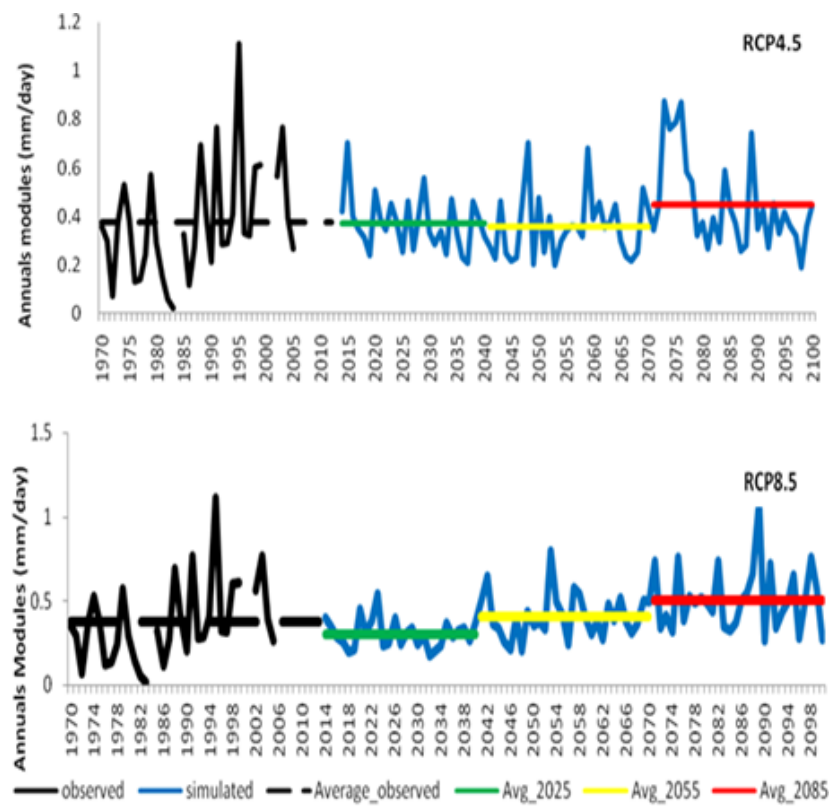

Figure 5. Evolution of the annual flow modules in the basin under the (RCP4.5 and 8.5) scenarios of the HIRHAM5 models as inputs to the 05 hydrological models.

model. Then, the different variations of the flows obtained in an alternative way with the set of 05-models used following the different scenarios show that, the future changes could be due to the anthropogenic activities of the man due in large part to the emissions of greenhouse gases and climate vulnerabilities.

\section{Conclusions}

This article focuses on the impacts of climate change on water availability in the oueme basin at Save. To this end AWBM model, the multi model AWBM-ModHyPMA-HBV and the set of five models have shown a fairly good capacity for simulating flows in the Oueme basin at Save. In addition, the simulation of flows with HIRHAM5 data as input to the hydrological models showed flow that vary with different horizon (2025, 2055 and 2085) under RCP4.5 and RCP8.5 scenarios.

Data availability. All the data used in this manuscript can be obtained by requesting from the corresponding author.

Author contributions. AC, EB, JZ, EO, EAA, EIB, and AA designed the study, developed the methodology and wrote the manuscript; Amedée Chabi performed the field work, collected the data and conducted the computer analysis.
Competing interests. The contact author has declared that neither they nor their co-authors have any competing interests.

Disclaimer. Publisher's note: Copernicus Publications remains neutral with regard to jurisdictional claims in published maps and institutional affiliations.

Special issue statement. This article is part of the special issue "Hydrology of Large River Basins of Africa". It is a result of the 4th International Conference on the "Hydrology of the Great Rivers of Africa", Cotonou, Benin, 13-20 November 2021.

\section{References}

Afouda, A. and Alamou, E.: Hydrologique basé sur le principe de moindre action (MODHYPMA), Ann. Sci. Agron. Bénin, 13, 23-45, 2010.

Afouda, A., Ould Baba Sy, M., Gaye, A. T., Cabral, A., Nazoumou, Y., Compaore, A. J., and Sanoussi, R.: Impact of Climate Change and Variability on Water Resources in West African Watersheds, What Are the Prospects?, Synthesis Report-Writeshop: Dakar, Senegal, 2007.

Akognongbe, A.: Contribution à l'étude de la caractérisation hydropluviométrique avec le modèle GR4J sur le bassin de l'Ouémé à Savè et Atchérigbé, Mémoire de maîtrise en géographie, UAC., 79 pp., 2007.

Bergström, S. and Forsman, A.: Development of a conceptual deterministic rainfall runoff model, Nordic Hydrology, 14, 147-170, 1973.

Boughton, W. C.: A hydrograph-based model for estimating the water yield of ungauged catchments, in: Proceedings of the 1993 Hydrology and Water Resources Conference, Institution of Engineers, Australia, National Conference Publication no., 93/14, 317-324, 1993.

Boyle, D.: Multicriteria calibration of hydrological models, $\mathrm{PhD}$ thesis, Dep. of Hydrol. and Water Resour., Univ. Of Ariz., Tucson, 2001.

Chiew, F. H. S. and Siriwardena, L.: Estimation of SIMHYD parameter values for application in ungauged catchments, in: MODSIM 2005 International Congress on Modelling and Simulation, Modelling and Simulation Society of Australia and New Zealand, Melbourne, Australia, 2883-2889, 2005.

IPCC: Impact, adaptation and vulnerability. Contribution of working Group II to the fourth assessment report of the intergovnmental Panel on Climate Change, 2007.

IPCC: Impacts, Adaptation, and vulnerability, Contribution of Working Group II to the Fifth Assessment Report of the Intergovernmental Panel on Climate Change, Cambridge University Press, Cambridge, United Kingdom and New York, NY, USA, 2014.

Nash, J. E. and Sutcliffe, J. V.: River flow forecasting through conceptual models part I - A discussion of principles, J. Hydrol., 10, 282-290, 1970.

Obada, E., Alamou, A. E., Chabi, A., Zandagba, J., and Afouda, A.: Trends and Changes in Recent and Future Penman-Monteith 
Potential Evapotranspiration in Benin, Article published in Hydrology (MDPI), 18 pp, 2017.

Paturel, J. E. and Mahe, G.: 1896-2006 Sahelian annual rainfall variability and runoff increase of Sahelian RiversVariabilité des pluies annuelles au Sahel entre 1896 et 2006 et augmentation des écoulements des rivières sahéliennes, Comptes Rendus, Geosciences, 341, 538-546, https://doi.org/10.1016/j.crte.2009.05.002, 2009.

Perrin, C.: Vers une amélioration d'un modèle global pluie-débit au travers d'une approche comparative, Thèse de Doctorat, INPG: Grenoble, Cemagref, Antony, 530 pp., 2000.
Quae, J.-F. S.: S'adapter au changement climatique, Agriculture écosystèmes et territoires, France, EdiTionS QuAE, 282 pp. 2013.

Sennikovs, J. and Bethers, U.: Statistical downscaling method of regional climate model results for hydrological modelling, in: 18 th World IMACS/MODSIM Congress, Australia, 2009.

Zandagba, J.: Impact des changements climatiques sur les ressources en eau du bassin de l'oueme à Savè, Master of Science en Hydrologie et Gestion Intégrée des Ressources à la CIPMAChaire UNESCO-Bénin/ Université d'Abomey-Calavi (UAC), République du Bénin, 2012. 